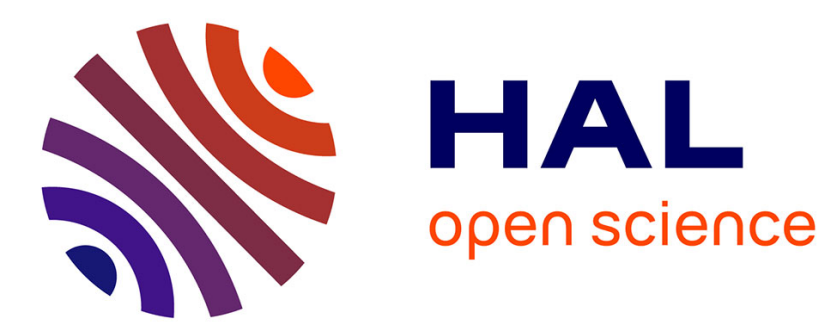

\title{
-glutathionylation of metallothioneins by nitrosative/oxidative stress
}

Manuela Casadei, Tiziana Persichini, Fabio Polticelli, Giovanni Musci, Marco Colasanti

\section{- To cite this version:}

Manuela Casadei, Tiziana Persichini, Fabio Polticelli, Giovanni Musci, Marco Colasanti. glutathionylation of metallothioneins by nitrosative/oxidative stress. Experimental Gerontology, 2008, 43 (5), pp.415. 10.1016/j.exger.2007.11.004 . hal-00499036

\section{HAL Id: hal-00499036 https://hal.science/hal-00499036}

Submitted on 9 Jul 2010

HAL is a multi-disciplinary open access archive for the deposit and dissemination of scientific research documents, whether they are published or not. The documents may come from teaching and research institutions in France or abroad, or from public or private research centers.
L'archive ouverte pluridisciplinaire HAL, est destinée au dépôt et à la diffusion de documents scientifiques de niveau recherche, publiés ou non, émanant des établissements d'enseignement et de recherche français ou étrangers, des laboratoires publics ou privés. 


\section{Accepted Manuscript}

$S$-glutathionylation of metallothioneins by nitrosative/oxidative stress

Manuela Casadei, Tiziana Persichini, Fabio Polticelli, Giovanni Musci, Marco

Colasanti

PII:

S0531-5565(07)00268-9

DOI:

10.1016/j.exger.2007.11.004

Reference:

EXG 8412

To appear in:

Experimental Gerontology

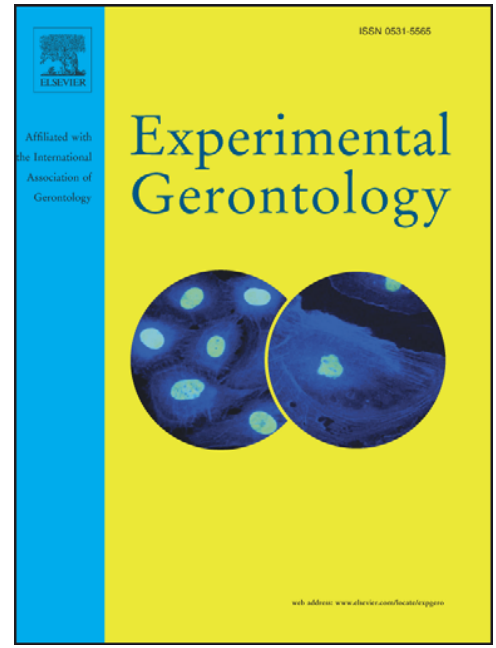

Received Date: $\quad 13$ September 2007

Revised Date: $\quad 31$ October 2007

Accepted Date: $\quad 6$ November 2007

Please cite this article as: Casadei, M., Persichini, T., Polticelli, F., Musci, G., Colasanti, M., S-glutathionylation of metallothioneins by nitrosative/oxidative stress, Experimental Gerontology (2007), doi: 10.1016/j.exger. 2007.11.004

This is a PDF file of an unedited manuscript that has been accepted for publication. As a service to our customers we are providing this early version of the manuscript. The manuscript will undergo copyediting, typesetting, and review of the resulting proof before it is published in its final form. Please note that during the production process errors may be discovered which could affect the content, and all legal disclaimers that apply to the journal pertain. 


\title{
$S$-glutathionylation of metallothioneins by nitrosative/oxidative stress
}

\author{
Manuela Casadei ${ }^{\text {a }}$, Tiziana Persichini ${ }^{\text {a }}$, Fabio $\underline{\text { Polticelli }}^{\text {a }}$, Giovanni Musci ${ }^{\text {b }}$ \\ and Marco Colasanti ${ }^{\mathrm{a}, *}$ \\ ${ }^{a}$ Dipartimento di Biologia, University ROMA TRE, Viale Marconi 446, 00146 Rome, Italy \\ ${ }^{b}$ Dipartimento di Scienze e Tecnologie Agro-alimentari, Ambientali e Microbiologiche, \\ University of Molise, Via de Sanctis, 86100 Campobasso, Italy.
}

* Corresponding author: Tel.: +3906 55176338; fax: +3906 55176321.

E-mail address: colasant@ uniroma3.it (M. Colasanti).

Running title: $S$-glutathionylation of MTs

Keywords: diamide; metallothioneins; nitric oxide; nitrosative/oxidative stress; $S$ glutathionylation; $S$-nitrosoglutathione. 


\begin{abstract}
Cystein residues within metallothionein (MT) structure have been shown to be particularly prone to $S$-nitrosylation. The objective of this study was to examine the possibility that MTs undergo $S$-glutathionylation under nitrosative/oxidative stress. MT from rabbit liver was treated with different concentrations of GSNO, diamide plus GSH or $\mathrm{H}_{2} \mathrm{O}_{2}$ plus GSH. Parallel sets of samples were treated with $10 \mathrm{mM}$ DTT for $30 \mathrm{~min}$ at $37^{\circ} \mathrm{C}$ to reduce mixed disulphides. Incubations were then processed for Western blot or dotimmunobinding assay. Western blot with anti-MT or anti-GSH were also performed on peripheral blood mononuclear cell extracts. Structural aspects of $S$-glutathionylation of MTs were also examined. Treatment with GSNO, diamide/GSH or $\mathrm{H}_{2} \mathrm{O}_{2} / \mathrm{GSH}$ induced a dosedependent increase in the levels of MT S-glutathionylation. This effect was completely reversed by treatment with the reducing agent DTT, indicating that $S$-glutathionylation of MT protein was related to formation of protein-mixed disulphides. Structural analysis of rat MT indicated that $\underline{\mathrm{Cys}}$ residues located in the $\mathrm{N}$-terminal domain of the protein are the likely targets for $S$-glutathionylation, both for their solvent accessibility and electrostatics induced reactivity. $S$-glutathionylation of MT, given its reversibility, would provide protection from irreversible oxidation of Cys residues, thus representing a mechanism of high potential biological relevance.
\end{abstract}




\section{Introduction}

Nitric oxide (NO) is a signaling molecule involved in several diverse physiological and pathological processes. Synthesized from L-arginine by three isoforms of the enzyme nitric oxide synthase (NOS) (Moncada and Palmer, 1991), NO is now known to control vascular smooth muscle tone, to inhibit platelet and inflammatory cell adhesion and activation, and to be a transmitter at non-adrenergic non-cholinergic synapses (Moncada et al., 1991; Quinn et al., 1995). NO has been also revealed to modulate apoptosis, in a variety of cell types, including human inflammatory cells (Taylor et al., 2003).

The wide variety of effects of NO is achieved, among others, through its specific interactions with cysteine-containing proteins (Stamler et al., 2001). The reversible attachment of NO to thiols, a covalent modification known as $S$-nitrosylation, represents most of the effects of NO on the activity of proteins (with the exclusion of metal-containing proteins). It has often been suggested that $S$-nitrosothiols represent a more stable metabolite of NO that can either be stored or transported, although the evidence for this is sparse (Hogg 2002). The abundance of GSH (0.5 to $10 \mathrm{mM})$ in the intracellular compartment renders the formation of $S$-nitrosoglutathione (GSNO), structurally the simplest $S$-nitrosothiol, kinetically favorable (Singh et al., 1996). GSNO can promote $S$-glutathionylation, i.e., the formation of mixed disulfides between protein thiol and GSH (Giustarini et al., 2005). Otherwise, $S$ glutathionylated proteins may be generated following the protein thiol groups activation by oxidative/nitrosative modifications to give thiyl radical, sulphenic acid, or protein $S$ nitrosothiol/S-nitrosylated protein (Giustarini et al., 2004). These modifications may be stable as such or react with GSH to form mixed disulphides (i.e., $S$-glutathionylated proteins). All these modifications are reversible and can be reverted by an increase in the GSH/GSSG ratio, reduced thiols, or enzymatic reactions (Giustarini et al., 2004). Evidence suggests that protein $S$-glutathionylation, being characterized by sensitivity, specificity and reversibility, might be a 
common mechanism for the global regulation of protein functions in different cellular types (Giustarini et al., 2004; Klatt and Lamas, 2000). In particular, it has been focused the role of $S$-glutathionylation as a mechanism of redox-mediated signal transduction as well as an adaptive cellular response protecting critical regulatory proteins from permanent loss of function, as a consequence of oxidative and nitrosative stress (Klatt and Lamas, 2000).

Metallothioneins (MTs) are a family of small proteins $(6-7 \mathrm{kDa})$ with a high content

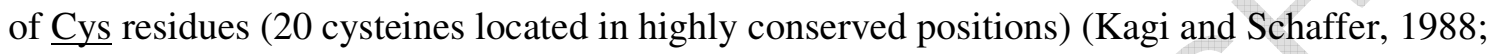
Vasak and Hasler, 2000), which allows these proteins to coordinate multiple mono $\left(\mathrm{Cu}^{+}, \mathrm{Ag}^{+}\right)$ or divalent metals $\left(\mathrm{Zn}^{2+}, \mathrm{Cd}^{2+}\right)$. Interestingly, NO has been shown to induce $S$-nitrosylation of Cys residues of intracellular MTs and consequent $\mathrm{Zn}^{2+}$ or $\mathrm{Cd}^{2+}$ release both in vitro (Aravindakumar et al., 1999; Kroncke et al., 1994; Misra et al., 1996; Zangger et al., 2001) and in vivo (Katakai et al., 2001; Pearce et al., 2000b; Pearce et al., 2000a; Schwarz et al., 1995). It is tempting to speculate that the same "activated" Cys residues of MTs are highly reactive to $S$-glutathionylation as well.

In this study, we examined the possibility that MTs undergo $S$-glutathionylation under nitrosative/oxidative stress. To this purpose, we exposed the MT to GSNO and other oxidizing agents (diamide or hydrogen peroxide in the presence of GSH), and performed Western blot and dot-immunobinding assay. Structural aspects of $S$-glutathionylation of MTs were also examined. 


\section{Materials and methods}

\subsection{Chemicals and reagents}

Metallothionein (MT) from rabbit liver, bovine serum albumin (BSA), $N$ ethylmaleimide (NEM), and protease inhibitors (leupeptin, phenylmethylsulfonyl fluoride and protease inhibitor cocktail) were purchased from Sigma-Aldrich (Milan, Italy). A\&G-

Sepharose beads and protein molecular marker were from Amersham Biosciences (Uppsala, Sweden). The redox reagents reduced L-glutathione (GSH), diamide, hydrogen peroxide $\left(\mathrm{H}_{2} \mathrm{O}_{2}\right)$ and 2,4-dithiothreitol (DTT) were also obtained from Sigma-Aldrich (Milan, Italy). Fresh solutions of GSH and diamide were bubbled with $\mathrm{N}_{2}$ and stored in aliquots at $-80^{\circ} \mathrm{C}$. To avoid spontaneous oxidation of GSH and diamide, aliquots were thawed only once and the unused portion was discarded. Mouse anti-GSH monoclonal antibody was from Virogen (Watertown, MA, USA). Mouse anti-MT monoclonal antibody was purchased from Stressgen (Assay Designs, Inc. Michigan, Ann Arbor, MI, USA) and rabbit anti-MT polyclonal antibody was from Santa Cruz Biotechnology, Inc. (Santa Cruz, CA, USA). Horseradish peroxidase-conjugated anti-mouse IgG was from Calbiochem (La Jolla, CA, USA). All other reagents were of analytical grade from commercial sources.

\subsection{Synthesis of GSNO}

S-nitrosoglutathione (GSNO) was synthesized by combining equimolar concentrations (200 mM) of GSH and $\mathrm{NaNO}_{2}$ in $0.5 \mathrm{M} \mathrm{HCl}$ at room temperature. After 5 min of incubation, the solution was neutralized by addition of $\mathrm{NaOH}(200 \mathrm{mM})$. Stock solutions of GSNO were bubbled with $\mathrm{N}_{2}$ and stored in aliquots at $-80^{\circ} \mathrm{C}$. 


\subsection{Diamide, $\mathrm{H}_{2} \mathrm{O}_{2}$ and $\mathrm{GSNO}$ treatment of $\mathrm{MT}$}

MT from rabbit liver (4 $\mu \mathrm{g} / \mathrm{assay})$ was diluted in lysis buffer $(50 \mathrm{mM}$ Tris-HCl $\mathrm{pH}$ 7.4, 2 mM EGTA, 2 mM EDTA, 1\% (v/v) Triton X-100 and protease inhibitors). MT was then treated with different concentrations of GSNO, diamide plus GSH or $\mathrm{H}_{2} \mathrm{O}_{2}$ plus GSH, for 30 $\min$ at $37^{\circ} \mathrm{C}$. Reactions were stopped by addition of $5 \mathrm{mM}$ NEM to block unreacted thiol groups, and mixtures were incubated for additional $30 \mathrm{~min}$ at $37^{\circ} \mathrm{C}$. Parallel sets of samples were co-treated with $10 \mathrm{mM}$ DTT for $30 \mathrm{~min}$ at $37^{\circ} \mathrm{C}$, to reduce mixed disulphides. Incubations were then processed for Western blot or dot-immunobinding assay as described below.

\subsection{Immunoprecipitation of $M T$}

Peripheral Blood Mononuclear Cells (PBMC) from voluntary healthy subjects were rinsed in cold PBS and lysed in lysis buffer supplemented with $50 \mathrm{mM}$ NEM. Cell lysates (50 $\mu \mathrm{g}$ ) were incubated with $10 \mu \mathrm{l}$ of polyclonal antibody raised against MT (Santa Cruz Biotechnology, Inc., Santa Cruz, CA, USA) at $4^{\circ} \mathrm{C}$ overnight on a rocker platform. Immunoprecipitates were adsorbed to protein A\&G-Sepharose at $4^{\circ} \mathrm{C}$ for $2 \mathrm{~h}$, collected by centrifugation at $270 \times \mathrm{g}$ for $10 \mathrm{~min}$ at $4^{\circ} \mathrm{C}$, washed three times with lysis buffer, and eluted from beads with $5 \%$ SDS. Samples were then analyzed by non-reducing SDS-PAGE as described below.

\subsection{Identification of S-glutathionylated MT by Western Blot}

Protein samples were dissolved in a non-reducing sample buffer $(62.5 \mathrm{mM}$ Tris- $\mathrm{HCl}$, pH 6.8, 10\% glycerol, 5\% SDS, 0.05\% bromophenol blue) supplemented with 5 mM NEM, were denatured at $100^{\circ} \mathrm{C}$ for $5 \mathrm{~min}$, and were separated on a $15 \%$ sodium dodecyl sulphatepolyacrylamide gel. In a parallel set of samples, $10 \mathrm{mM}$ DTT was added to the sample buffer. 
After electrophoresis, proteins were transferred to a polyvinylidene difluoride (PVDF) membrane and nonspecific binding was blocked by incubation in 3\% BSA diluted in TBST. Membranes were then probed with primary monoclonal antibodies against MT or GSH, diluted 1:1000 in blocking buffer. After washing, blots were incubated with secondary antibodies conjugated to horseradish peroxidase (1:15000 dilution in blocking solution). Protein-antibody reactions were detected with an ECL kit (Amersham Biosciences). For the quantification of $S$-glutathionylation levels, films were digitally scanned and scans were analyzed with the Multi-Analyst PC version 1.1 program (Bio-Rad Laboratories S.r.l., Milan, Italy).

\subsection{Identification of S-glutathionylated MT by Dot-immunobinding assay}

Protein samples were diluted in a denaturing solution $(62.5 \mathrm{mM}$ Tris- $\mathrm{HCl} \mathrm{pH} 7.5$, $0.05 \%(\mathrm{w} / \mathrm{v}) \mathrm{SDS}$ ) without reducing agents, containing $5 \mathrm{mM}$ NEM. In a parallel set of samples $10 \mathrm{mM}$ DTT was added to the denaturing solution. Samples were then subjected to dot-immunobinding assay. Immunodetection of protein $S$-glutathionylation was performed as described for Western blot analysis. Estimates of the relative $S$-glutathionylation levels were obtained dividing the optical density of the glutathionylated MT spot by the optical density of the MT spot (Bio-Rad Multianalyst). The statistical analysis of the data for single comparisons was performed by Student's t test.

\subsection{Structural analysis}

Structural determinants of Cys residues reactivity have been analyzed using rat liver MT three-dimensional structure (PDB code 4MT2) (Braun et al., 1992). The accessible surface area of Cys S $\gamma$ atoms has been calculated using Michael Sanner's MSMS program (available at http://www.scripps.edu/ sanner/), with a $1.4 \AA$ probe size. 


\section{Results}

To verify whether MT is susceptible to $S$-glutathionylation under oxidative/nitrosative stress conditions, we exposed commercially available MT from rabbit liver to GSNO, and to other oxidants (i.e., diamide or $\mathrm{H}_{2} \mathrm{O}_{2}$, in the presence of GSH).

MT was first treated with varying concentrations of GSNO $(0,0.25,0.5,1,2$, and $5 \mathrm{mM})$ and tested by Western blot analysis using monoclonal antibodies raised against GSH or MT to probe the membrane. Results shown in Fig. 1A,C suggest that the appearance of $S$ glutathionylated MT induced by the oxidative stress condition correlates with the increasing GSNO concentration, the maximal effect being observed at $2 \mathrm{mM}$ nitrosothiol.

Glutathionylated MT was found to run mainly as a $14 \mathrm{kDa}$ band (Fig. 1A), with a minor portion running at $28 \mathrm{kDa}$ at the highest GSNO concentration (data not shown). When the membrane was probed with an anti-MT antibody, a 6-7-kDa immunoreactive band was mainly detected in untreated MT (Fig. 1B, lane 1) as well as in GSNO-treated MT (Fig. 1B, lanes 2-6), consistent with the reported molecular weight for the monomeric form of MT. Interestingly, the treatment with GSNO induced the progressive appearance of lower mobility immunoreactive bands, with molecular masses (multiple of 6-7 kDa) apparently corresponding to different oligomeric forms of MT . As shown by the densitometric analysis in Fig. 1D, the MT dimer running at $14 \mathrm{kDa}$ was the main product. These results are consistent with the well-known tendency of MT protein to form stable complexes and aggregates under oxidative stress conditions (Hou et al., 2000; Oppermann et al., 2001;

Suzuki et al., 1998; Vallee et al., 1991; Whitacre 1996; Wilhelmsen et al., 2002), and suggest that $S$-glutathionylation mainly provokes dimerization of MT. $\underline{\text { In order to validate the results }}$ obtained by SDS-PAGE (Fig. 1A-D) and actually to show at once the total amount of immunoreactive MT, a simpler analysis of MT glutathionylation could be performed by using a dot blot procedure. Again, MT was treated with varying concentrations of GSNO. After 30 
min of incubation samples were treated with either NEM, to block residual free thiols, or with DTT, to reduce any $S$-thiolated cystein. Detection of $S$-glutathionylated MT was obtained analyzing samples treated with GSNO by dot-immunobinding assay using monoclonal antibodies raised against GSH or MT. As expected, results (shown in Fig. 1E,G) were similar to those obtained by Western blot, in that the treatment with GSNO induced progressively higher levels of MT S-glutathionylation. To investigate whether GSNO was inducing the formation of protein-mixed disulphides on MT, samples were treated with the reducing agent DTT after exposure to GSNO. As shown in Fig. 1F, 10 mM DTT was able to completely reverse $S$-glutathionylation, as demonstrated by the disappearance of the immunostained spots, suggesting that mixed disulfides are formed in the presence of GSNO.

Next, MT was treated with different concentrations of the highly specific thiol oxidant diamide $(0,0.1,0.2,0.5,1$, and $2 \mathrm{mM})$ and of the physiologically occurring oxidant $\mathrm{H}_{2} \mathrm{O}_{2}(0$, $0.2,0.5,1,2$, and $5 \mathrm{mM}$ ), both in the presence of $1 \mathrm{mM} \mathrm{GSH}$. Again reversibility was assessed by addition of the sulfhydryl reducing agent DTT.Consistent with data obtained with GSNO treatment, both diamide (Fig. 2A,B) and $\mathrm{H}_{2} \mathrm{O}_{2}$ (Fig. 2C,D) were able to induce a dose-dependent increase of $S$-glutathionylated MT in the presence of GSH. Again, $10 \mathrm{mM}$ DTT completely reversed $S$-glutathionylation of MT induced by diamide and $\mathrm{H}_{2} \mathrm{O}_{2}$, as demonstrated by the disappearance of the immunostained spots (Fig. 2E and 2F, respectively). Data presented so far demonstrate that $S$-glutathionylation of MT can be induced in vitro by a number of nitrosating/oxidizing mixtures. The question now is whether MT can be found glutathionylated in vivo. To address this point, PBMC lysates were immunoprecipitated with a polyclonal antibody raised against MT, and immunoprecipitates were analyzed by Western blot. As shown in Fig. 3A, MT was found to be highly aggregated under our experimental conditions. Interestingly, MT was also reactive toward the anti-GSH antibody (Fig. 3B), suggesting that in vivo it is heavily glutathionylated. 
The molecular basis of susceptibility of rat MT to $S$-glutathionylation can be rationalized through comparison with the other well known modification of Cys residues, i.e., $S$ nitrosylation. It is well known that the structural environment of the NO-reactive cysteine $S \gamma$ atom is critical for the $S$-nitrosylation (Ascenzi et al., 2000). In fact, the solvent accessibility of the thiol group largely determines cysteine reactivity. In addition, the presence of basic residues in the vicinity of $\underline{\mathrm{Cys}}$ residues facilitates deprotonation of the thiol group, thus increasing its reactivity. Similar considerations can be applied to glutathionylation reactions which are dependent as well on the reactivity of the cysteine thiol group. With this concepts in mind, rat liver MT three-dimensional structure has been analyzed (PDB code 4MT2) (Braun et al., 1992) to uncover structural characteristics that allow to hypothesize the likely glutathionylation sites. First, the accessible surface area of $\underline{\mathrm{Cys}}$ residues Syatom has been measured. As can be seen from Table 1 and Fig. 4, only for three $\underline{C y s}$ residues the measured values are significantly different from zero: Cys7, Cys13 and Cys59. Two out of these three residues (i.e., Cys7 and Cys13) are located in the $N$-terminal domain of MT which has been previously shown to be the selective target of $S$-nitrosothiol formation (Zangger et al., 2001). Then, MT structure has been inspected to analyze the structural microenvironment of $\underline{\text { ys }}$ residues as far as the presence of basic and acidic residues is concerned. From Fig. 4 it can be seen that two Cys residues located in the $N$-terminal domain of MT, Cys19 and Cys21, are less than $5 \AA$ away from two Lys residues, Lys31 and Lys22. No other cysteine residue has charged residues in its immediate structural neighborhood. Based on the above considerations

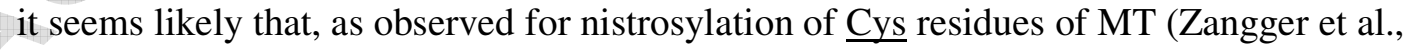
2001), the target for $S$-glutathionylation is represented by MT $N$-terminal domain $\underline{\text { Cys }}$ residues. 


\section{Discussion}

Oxidative/nitrosative stress conditions may cause chemical modifications on sensitive proteins. Such modifications, if irreversible, are usually associated with permanent loss of function and may lead to the elimination or to the accumulation of the damaged proteins. It has been proposed that reversible modifications, in particular at the $\underline{\text { Cys }}$ residues as $S$ glutathionylation, may have a dual role of protection from cysteine irreversible oxidation and modulation of protein function. The molecular mechanisms of protein function regulation by $S$-glutathionylation in response to oxidative and nitrosative stress have been previously reviewed by Klatt and Lamas (Klatt and Lamas, 2000). They put special attention to the role of $S$-glutathionylation in stress signaling pathways and in the adaptive cellular response to oxidative and/or nitrosative insult. In particular, they focus on the role of $S$-glutathionylation as a mechanism of redox-mediated signal transduction as well as an adaptive cellular response protecting critical regulatory molecules from permanent loss of function, as a consequence of oxidative and nitrosative stress. Note that the accumulation of oxidatively irreversibly modified proteins (e.g., carbonylated proteins) is an important hallmark of biological ageing and pathological situations that are associated with oxidative/nitrosative stress (Brigelius et al., 1983; Giustarini et al., 2004; Stadtman 2004; Stadtman and Berlett, 1998).

Although the biological function(s) of MTs still remain somewhat elusive (Palmiter 1998), they have been proposed to act as radical scavengers under oxidative stress (Maret 1995; Sato and Bremner, 1993; Thornalley and Vasak, 1985). It has been also reported that MTs play an important role in heavy metal detoxification (Cherian et al., 1994; Hamer 1986) and zinc homeostasis (Kagi and Schaffer, 1988; Li et al., 1980). The tight metal binding in the adomain has been hypothesized to be important for the detoxification of heavy metals, whereas the function of MTs in the homeostasis of zinc and copper has been attributed to the $\beta$ domain. Recently, it has been shown that an oxidoreductive mechanism modulates the 
affinity of zinc for the cysteine thiolate ligands and that key players are reduced glutathione, oxidized glutathione, and other oxidizing agents. In this regard, cysteines of metal thiolate clusters confer redox sensitivity to an otherwise redox inert metal ligand (e.g., $\mathrm{Zn}^{2+}$ ) and facilitate the potential of MTs to participate in intracellular signal transduction pathways (Jacob et al., 1998; Jiang et al., 1998; Maret 1995; Maret and Vallee, 1998). In this respect, the observation of NO-induced selective release of bound metals from MTs points to a possible physiological function of this interaction. In particular, MTs act as scavengers of free NO by forming S-nitrosothiols with a concomitant release of zinc from the $\beta$ domain (Zangger et al., 2001).

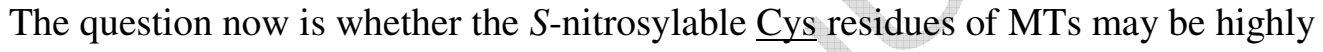
reactive to $S$-glutathionylation as well. In this study, $S$-glutathionylation of MTs under nitrosative/oxidative stress has been addressed by exposing the MT to three different oxidants (i.e., GSNO, diamide and $\mathrm{H}_{2} \mathrm{O}_{2}$ ) acting by different mechanisms. GSNO is the $S$-nitrosothiol of GSH and it could be the most relevant biological molecule to carry out nitrosation reactions under physiological conditions (Arnelle and Stamler, 1995; Meyer et al., 1994; Padgett and Whorton, 1995). Diamide, which is a strong oxidant with high specificity for thiols (Kosower and Kosower, 1995), and $\mathrm{H}_{2} \mathrm{O}_{2}$, a physiologically occurring oxidant, all have been shown to cause rapid, extensive, and reversible $S$-glutathionylation of a number of cell proteins (DalleDonne et al., 2005; Fratelli et al., 2002; Ghezzi et al., 2002; Kosower and Kosower, 1995; Rossi et al., 2006). Both Western blot and dot blot analyses have unequivocally shown that MT can be glutayhionylated in vitro. Moreover, it appears that glutathionylation is accompanied by polimerization of MT, suggesting that modification of $\underline{\text { Cys }}$ residues be one of the structural determinants at the basis of the well known tendency of MT to aggregate.

The immunochemical evidence for $S$-glutathionylation of MT in lysate samples was obtained by Western blot, using monoclonal antibodies raised to GSH as reported elsewhere 
(Dalle-Donne et al., 2003; Dalle-Donne et al., 2005; Kil and Park 2005; Pastore et al., 2003; Sparaco et al., 2006). It is interesting to note that MT was found to be highly aggregated in vivo, yet heavily glutathionylated. In this respect, while our data refer to in vitro conditions $\underline{\text { that most likely do not occur as such in vivo, nevertheless they constitute a valid model of }}$ physiological thiol modifications, unequivocally showing a link between cysteines modification and polymers formation.

The possibility that the same $\underline{\mathrm{Cys}}$ residues sensitive to $S$-nitrosylation may be reactive for $S$-glutathionylation has been evaluated by analyzing the structural aspects and the molecular details of the oxidative protein modification. Analysis of the three-dimensional structure of rat liver MT evidences that Cys residues of the N-terminal domain, given their solvent accessibility, are the likely targets of $S$-glutathionylation, taking also into account the higher bulkiness of glutathione as compared to NO. Further, the observation that two Cys residues of MT $N$-terminal domain have basic residues in their immediate neighborhood indicates that these residues can be more reactive, especially in the case that partial apo forms of MT are present.

From this viewpoint, $S$-glutathionylation of MT, given its reversibility, would provide protection from irreversible oxidation of Cys residues, thus representing a mechanism of high potential biological relevance. In fact, while $S$-nitrosylation does not prevent further and irreversible oxidation of Cys residues, $S$-glutathionylation can be reversed provided the GSH/GSSG ratio is high or, in other words, in conditions in which the oxidative stress within the cell has not reached a critical level. This process would regenerate the free thiol group of Cys residues thus restoring the metal binding ability and hence the biological function of MT. 


\section{Acknowledgements}

This study was supported by grants from EU Commission (Project ZINCAGE, n.

FOOD-CT-2003-506850) to M. Colasanti. 


\section{References}

Aravindakumar, C.T., Ceulemans, J., De Ley, M. 1999. Nitric oxide induces Zn2+ release from metallothionein by destroying zinc-sulphur clusters without concomitant formation of S-nitrosothiol. Biochem. J. 344 Pt 1, 253-258.

Arnelle, D.R. Stamler, J.S. 1995. NO+, NO, and NO- donation by S-nitrosothiols: implications for regulation of physiological functions by S-nitrosylation and acceleration of disulfide formation. Arch. Biochem. Biophys. 318, 279-285.

Ascenzi, P., Colasanti, M., Persichini, T., Muolo, M., Polticelli, F., Venturini, G., Bordo, D., Bolognesi, M. 2000. Re-evaluation of amino acid sequence and structural consensus rules for cysteine-nitric oxide reactivity. Biol. Chem. 381, 623-627.

Braun, W., Vasak, M., Robbins, A.H., Stout, C.D., Wagner, G., Kagi, J.H., Wuthrich, K. 1992. Comparison of the NMR solution structure and the X-ray crystal structure of rat metallothionein-2. Proc. Natl. Acad. Sci. U. S. A. 89, 10124-10128.

Brigelius, R., Muckel, C., Akerboom, T.P., Sies, H. 1983. Identification and quantitation of glutathione in hepatic protein mixed disulfides and its relationship to glutathione disulfide. Biochem. Pharmacol. 32, 2529-2534.

Cherian, M.G., Howell, S.B., Imura, N., Klaassen, C.D., Koropatnick, J., Lazo, J.S., Waalkes, M.P. 1994. Role of metallothionein in carcinogenesis. Toxicol. Appl. Pharmacol. 126, $1-5$.

Dalle-Donne, I., Giustarini, D., Colombo, R., Milzani, A., Rossi, R. 2005. Sglutathionylation in human platelets by a thiol-disulfide exchange-independent mechanism. Free Radic. Biol. Med. 38, 1501-1510.

Dalle-Donne, I., Giustarini, D., Rossi, R., Colombo, R., Milzani, A. 2003. Reversible Sglutathionylation of Cys 374 regulates actin filament formation by inducing structural changes in the actin molecule. Free Radic. Biol. Med. 34, 23-32.

Fratelli, M., Demol, H., Puype, M., Casagrande, S., Eberini, I., Salmona, M., Bonetto, V., Mengozzi, M., Duffieux, F., Miclet, E., Bachi, A., Vandekerckhove, J., Gianazza, E., Ghezzi, P. 2002. Identification by redox proteomics of glutathionylated proteins in oxidatively stressed human T lymphocytes. Proc. Natl. Acad. Sci. U. S. A. 99, 35053510 .

Ghezzi, P., Romines, B., Fratelli, M., Eberini, I., Gianazza, E., Casagrande, S., Laragione, T., Mengozzi, M., Herzenberg, L.A., Herzenberg, L.A. 2002. Protein glutathionylation: coupling and uncoupling of glutathione to protein thiol groups in lymphocytes under oxidative stress and HIV infection. Mol. Immunol. 38, 773-780. 
Giustarini, D., Milzani, A., Aldini, G., Carini, M., Rossi, R., Dalle-Donne, I. 2005. SNitrosation versus S-Glutathionylation of Protein Sulfhydryl Groups by SNitrosoglutathione. Antioxid. Redox. Signal. 7, 930-939.

Giustarini, D., Rossi, R., Milzani, A., Colombo, R., Dalle-Donne, I. 2004. Sglutathionylation: from redox regulation of protein functions to human diseases. J. Cell Mol. Med. 8, 201-212.

Hamer, D.H. 1986. Metallothionein. Annu. Rev. Biochem. 55, 913-951.

Hogg, N. 2002. The biochemistry and physiology of S-nitrosothiols. Annu. Rev. Pharmacol. Toxicol. 42, 585-600.

Hou, T., An, Y., Ru, B., Bi, R., Xu, X. 2000. Cysteine-independent polymerization of metallothioneins in solutions and in crystals. Protein Sci. 9, 2302-2312.

Jacob, C., Maret, W., Vallee, B.L. 1998. Control of zinc transfer between thionein, metallothionein, and zinc proteins. Proc. Natl. Acad. Sci. U. S. A. 95, 3489-3494.

Jiang, L.J., Maret, W., Vallee, B.L. 1998. The glutathione redox couple modulates zinc transfer from metallothionein to zinc-depleted sorbitol dehydrogenase. Proc. Natl. Acad. Sci. U. S. A. 95, 3483-3488.

Kagi, J.H. Schaffer, A. 1988. Biochemistry of metallothionein. Biochemistry. 27, 8509-8515.

Katakai, K., Liu, J., Nakajima, K., Keefer, L.K., Waalkes, M.P. 2001. Nitric oxide induces metallothionein (MT) gene expression apparently by displacing zinc bound to MT. Toxicol. Lett. 119, 103-108.

Kil, I.S. Park, J.W. 2005. Regulation of mitochondrial NADP+-dependent isocitrate dehydrogenase activity by glutathionylation. J. Biol. Chem. 280, 10846-10854.

Klatt, P. Lamas, S. 2000. Regulation of protein function by S-glutathiolation in response to oxidative and nitrosative stress. Eur. J. Biochem. 267, 4928-4944.

Kosower, N.S. Kosower, E.M. 1995. Diamide: an oxidant probe for thiols. Methods Enzymol. 251, 123-133.

Kroncke, K.D., Fehsel, K., Schmidt, T., Zenke, F.T., Dasting, I., Wesener, J.R., Bettermann, H., Breunig, K.D., Kolb-Bachofen, V. 1994. Nitric oxide destroys zinc-sulfur clusters inducing zinc release from metallothionein and inhibition of the zinc finger-type yeast transcription activator LAC9. Biochem. Biophys. Res. Commun. 200, 1105-1110.

Li, T.Y., Kraker, A.J., Shaw, C.F., III, Petering, D.H. 1980. Ligand substitution reactions of metallothioneins with EDTA and apo-carbonic anhydrase. Proc. Natl. Acad. Sci. U. S. A. $77,6334-6338$. 
Maret, W. 1995. Metallothionein/disulfide interactions, oxidative stress, and the mobilization of cellular zinc. Neurochem. Int. 27, 111-117.

Maret, W. Vallee, B.L. 1998. Thiolate ligands in metallothionein confer redox activity on zinc clusters. Proc. Natl. Acad. Sci. U. S. A. 95, 3478-3482.

Meyer, D.J., Kramer, H., Ozer, N., Coles, B., Ketterer, B. 1994. Kinetics and equilibria of Snitrosothiol-thiol exchange between glutathione, cysteine, penicillamines and serum albumin. FEBS Lett. 345, 177-180.

Misra, R.R., Hochadel, J.F., Smith, G.T., Cook, J.C., Waalkes, M.P., Wink, D.A. 1996. Evidence that nitric oxide enhances cadmium toxicity by displacing the metal from metallothionein. Chem. Res. Toxicol. 9, 326-332.

Moncada, S. Palmer, R.M. 1991. Biosynthesis and actions of nitric oxide. Semin. Perinatol. $15,16-19$.

Moncada, S., Palmer, R.M., Higgs, E.A. 1991. Nitric oxide: physiology, pathophysiology, and pharmacology. Pharmacol. Rev. 43, 109-142.

Oppermann, B., Zhang, W., Magabo, K., Kantorow, M. 2001. Identification and spatial analysis of metallothioneins expressed by the adult human lens. Invest Ophthalmol. Vis. Sci. 42, 188-193.

Padgett, C.M. Whorton, A.R. 1995. S-nitrosoglutathione reversibly inhibits GAPDH by Snitrosylation. Am. J. Physiol. 269, C739-C749.

Palmiter, R.D. 1998. The elusive function of metallothioneins. Proc. Natl. Acad. Sci. U. S. A. $95,8428-8430$.

Pastore, A., Tozzi, G., Gaeta, L.M., Bertini, E., Serafini, V., Di Cesare, S., Bonetto, V., Casoni, F., Carrozzo, R., Federici, G., Piemonte, F. 2003. Actin glutathionylation increases in fibroblasts of patients with Friedreich's ataxia: a potential role in the pathogenesis of the disease. J. Biol. Chem. 278, 42588-42595.

Pearce, L.L., Gandley, R.E., Han, W., Wasserloos, K., Stitt, M., Kanai, A.J., McLaughlin, M.K., Pitt, B.R., Levitan, E.S. 2000a. Role of metallothionein in nitric oxide signaling as revealed by a green fluorescent fusion protein. Proc. Natl. Acad. Sci. U. S. A. 97, 477-482.

Pearce, L.L., Wasserloos, K., St Croix, C.M., Gandley, R., Levitan, E.S., Pitt, B.R. 2000b. Metallothionein, nitric oxide and zinc homeostasis in vascular endothelial cells. J. Nutr. 130, 1467S-1470S.

Pettersen, E.F., Goddard, T.D., Huang, C.C., Couch, G.S., Greenblatt, D.M., Meng, E.C., Ferrin, T.E. 2004. UCSF Chimera--a visualization system for exploratory research and analysis. J. Comput. Chem. 25, 1605-1612. 
Quinn, A.C., Petros, A.J., Vallance, P. 1995. Nitric oxide: an endogenous gas. Br. J. Anaesth. $74,443-451$.

Rossi, R., Dalle-Donne, I., Milzani, A., Giustarini, D. 2006. Oxidized forms of glutathione in peripheral blood as biomarkers of oxidative stress. Clin. Chem. 52, 1406-1414.

Sato, M. Bremner, I. 1993. Oxygen free radicals and metallothionein. Free Radic. Biol. Med. $14,325-337$.

Schwarz, M.A., Lazo, J.S., Yalowich, J.C., Allen, W.P., Whitmore, M., Bergonia, H.A., Tzeng, E., Billiar, T.R., Robbins, P.D., Lancaster, J.R., Jr., . 1995. Metallothionein protects against the cytotoxic and DNA-damaging effects of nitric oxide. Proc. Natl. Acad. Sci. U. S. A. 92, 4452-4456.

Singh, R.J., Hogg, N., Joseph, J., Kalyanaraman, B. 1996. Mechanism of nitric oxide release from S-nitrosothiols. J. Biol. Chem. 271, 18596-18603.

Sparaco, M., Gaeta, L.M., Tozzi, G., Bertini, E., Pastore, A., Simonati, A., Santorelli, F.M., Piemonte, F. 2006. Protein glutathionylation in human central nervous system: potential role in redox regulation of neuronal defense against free radicals. J. Neurosci. Res. 83, 256-263.

Stadtman, E.R. 2004. Role of oxidant species in aging. Curr. Med. Chem. 11, 1105-1112.

Stadtman, E.R. Berlett, B.S. 1998. Reactive oxygen-mediated protein oxidation in aging and disease. Drug Metab Rev. 30, 225-243.

Stamler, J.S., Lamas, S., Fang, F.C. 2001. Nitrosylation. the prototypic redox-based signaling mechanism. Cell. 106, 675-683.

Suzuki, J.S., Kodama, N., Molotkov, A., Aoki, E., Tohyama, C. 1998. Isolation and identification of metallothionein isoforms (MT-1 and MT-2) in the rat testis. Biochem. J. 334 ( Pt 3), 695-701.

Taylor, E.L., Megson, I.L., Haslett, C., Rossi, A.G. 2003. Nitric oxide: a key regulator of myeloid inflammatory cell apoptosis. Cell Death. Differ. 10, 418-430.

Thornalley, P.J. Vasak, M. 1985. Possible role for metallothionein in protection against radiation-induced oxidative stress. Kinetics and mechanism of its reaction with superoxide and hydroxyl radicals. Biochim. Biophys. Acta. 827, 36-44.

Vallee, B.L., Coleman, J.E., Auld, D.S. 1991. Zinc fingers, zinc clusters, and zinc twists in DNA-binding protein domains. Proc. Natl. Acad. Sci. U. S. A. 88, 999-1003.

Vasak, M. Hasler, D.W. 2000. Metallothioneins: new functional and structural insights. Curr. Opin. Chem. Biol. 4, 177-183. 
Whitacre, C.M. 1996. Application of Western blotting to the identification of metallothionein binding proteins. Anal. Biochem. 234, 99-102.

Wilhelmsen, T.W., Olsvik, P.A., Hansen, B.H., Andersen, R.A. 2002. Evidence for oligomerization of metallothioneins in their functional state. J. Chromatogr. A. 979, 249-254.

Zangger, K., Oz, G., Haslinger, E., Kunert, O., Armitage, I.M. 2001. Nitric oxide selectively releases metals from the amino-terminal domain of metallothioneins: potential role at inflammatory sites. FASEB J. 15, 1303-1305. 
Table 1. Solvent accessible surface area of rat MT $\underline{\text { Cys }}$ residues Syatom ${ }^{a}$

Residue Surface Area

Cys5 $\quad 0.000$

Cys7 $\quad 4.388$

Cys13 15.503

Cys $15 \quad 0.000$

Cys19 0.000

Cys21 0.337

Cys24 0.000

Cys26 $\quad 0.000$

Cys29 0.000

Cys33 0.052

Cys34 0.000

$\begin{array}{ll}\text { Cys36 } & 0.490\end{array}$

Cys37 0.000

Cys41 0.000

Cys44 0.000

Cys48 $\quad 0.000$

Cys50 $\quad 0.000$

Cys57 0.000

Cys59 $\quad 6.342$

$\begin{array}{ll}\text { Cys60 } & 0.000\end{array}$

${ }^{\mathrm{a}}$ Surface area values are expressed in $\AA^{2}$ units. 


\section{FIGURE LEGENDS}

Fig. 1. Western blot and dot blot analyses of $S$-glutathionylation of MT induced by GSNO treatment. Treatment of MT with GSNO induces a dose-dependent $S$-glutathionylation of MT (A) and the progressive appearance of immunoreactive bands with molecular masses (multiple of 6-7 kDa) apparently corresponding to different oligomeric forms of MT (B). For quantification, glutathionylated MT (C) and MT (D) bands have been analyzed with the Multi-Analyst PC version 1.1 program. Dot blot analysis confirms the GSNO-induced $S$ glutathionylation of MT in the presence of $5 \mathrm{mM}$ NEM, an effect being reversed by treatment with DTT (E). (G) Estimates of the amounts of glutathionylated MT (MTS-SG) have been obtained by dividing the optical density of the area of the relative spot with the same area of the MT protein spot (F). After setting to 1 the ratio MTS-SG/MT from untreated MT (lane 1), values for the other samples have been calculated relative to it. Results are representative of three independent experiments. See Materials and methods for further details.

Fig. 2. Dot blot analysis of $S$-glutathionylation of MT induced by treatment with diamide and $\mathrm{H}_{2} \mathrm{O}_{2}$. Treatment of MT with diamide (A) and $\mathrm{H}_{2} \mathrm{O}_{2}$ (B), both in the presence of $1 \mathrm{mM} \mathrm{GSH}$, is able to induce a dose-dependent increase of $S$-glutathionylation. DTT (10 mM) completely reverses $S$-glutathionylation of MT induced by diamide (E) and $\mathrm{H}_{2} \mathrm{O}_{2}(\mathrm{~F})$. Estimates of the relative amounts of glutathionylated MT induced by diamide (C) and $\mathrm{H}_{2} \mathrm{O}_{2}$ (D) have been obtained by measuring the optical density of the area of MTS-SG spot. After setting to 1 the ratio MTS-SG/MT from untreated MT (lane 1), values for the other samples have been calculated relative to it. Results are representative of three independent experiments. See Materials and methods for further details. 
Fig. 3. Western blot analysis of $S$-glutathionylation of MT in peripheral blood mononuclear cell extracts. Lysates of PBMC from voluntary healthy donors (lanes 1-8) were immunoprecipitated with a polyclonal antibody raised against MT, and immunoprecipitates were analyzed by Western blot using monoclonal antibodies against MT or GSH. Under our experimental conditions, MT is found to be highly aggregated (A) and heavily glutathionylated (B). See Materials and methods for further details.

Fig. 4. Schematic representation of the three-dimensional structure of rat MT. For clarity only

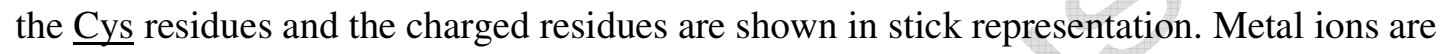
shown as spheres. The figure was made using Chimera (Pettersen et al., 2004). 
Fig.1

Converted by Total Image Converter - (no stamps are applied by registered version)

WESTERN BLOT

Anti-GSH

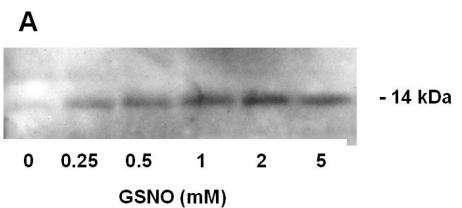

Anti-MT

B

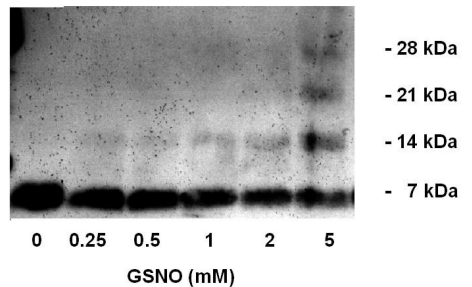

D

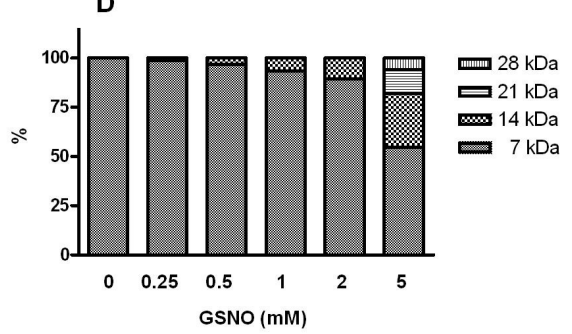

DOT BLOT
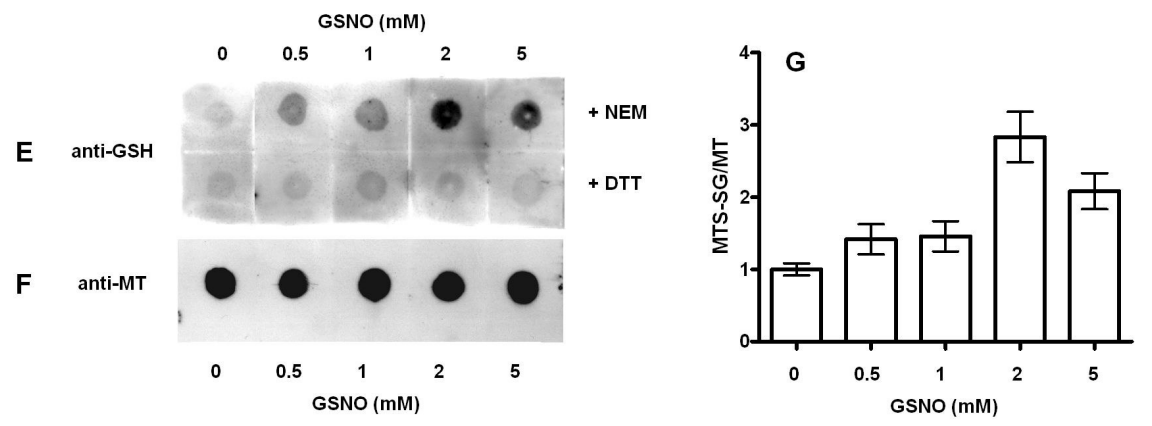
Fig.2
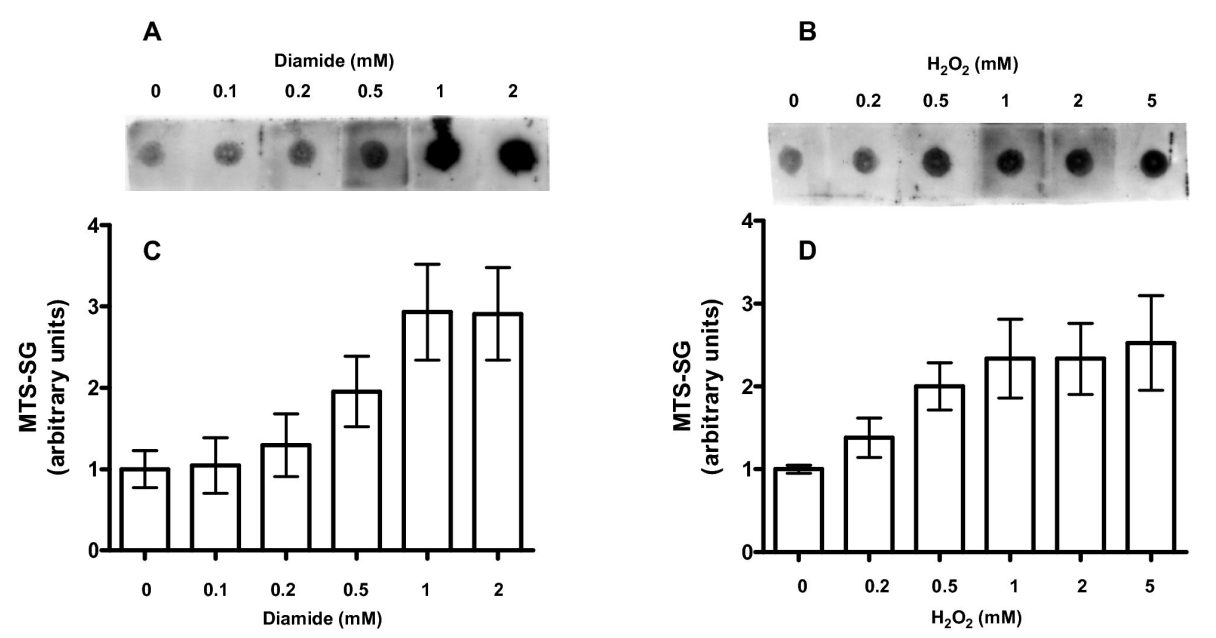

\begin{tabular}{|l|c|c|c|c|c|c|}
\hline Diamide (mM) & 0 & 0 & 0.1 & 0.1 & 0.5 & 0.5 \\
\hline DTT & - & + & - & + & - & + \\
\hline NEM & + & - & + & - & + & - \\
\hline \\
E Diamide \\
\end{tabular}
\begin{tabular}{|l|c|c|c|c|c|c|}
\hline$\quad \mathrm{H}_{2} \mathrm{O}_{2}$ \\
$\mathrm{H}_{2} \mathrm{O}_{2}(\mathrm{mM})$ & 0 & 0 & 0.1 & 0.1 & 0.5 & 0.5 \\
\hline $\mathrm{DTT}$ & - & + & - & + & - & + \\
\hline $\mathrm{NEM}$ & + & - & + & - & + & - \\
\hline
\end{tabular}

Figure 2 
Fig.3

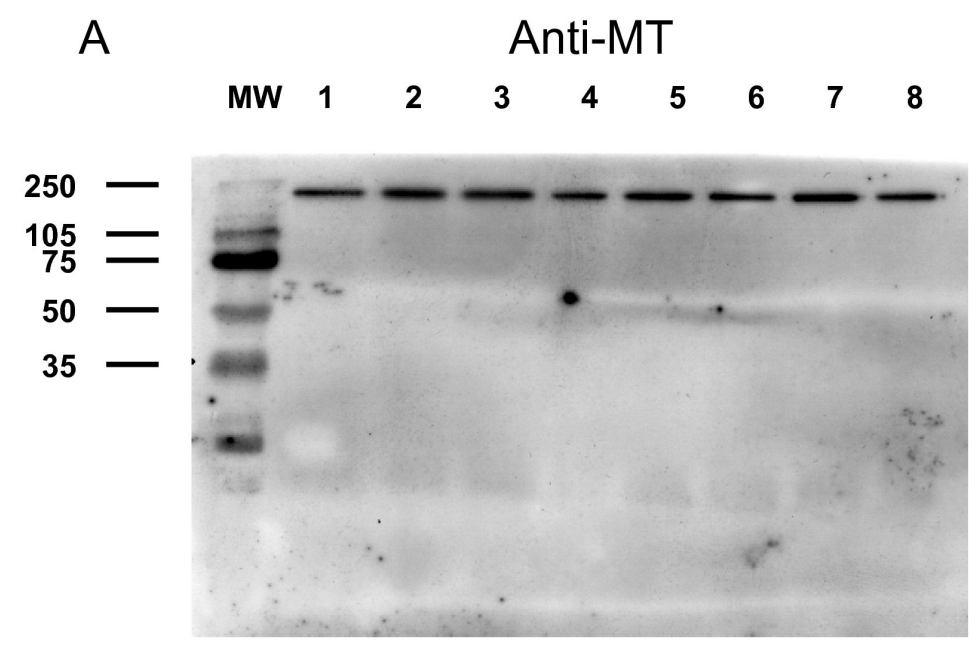

B Anti-GSH

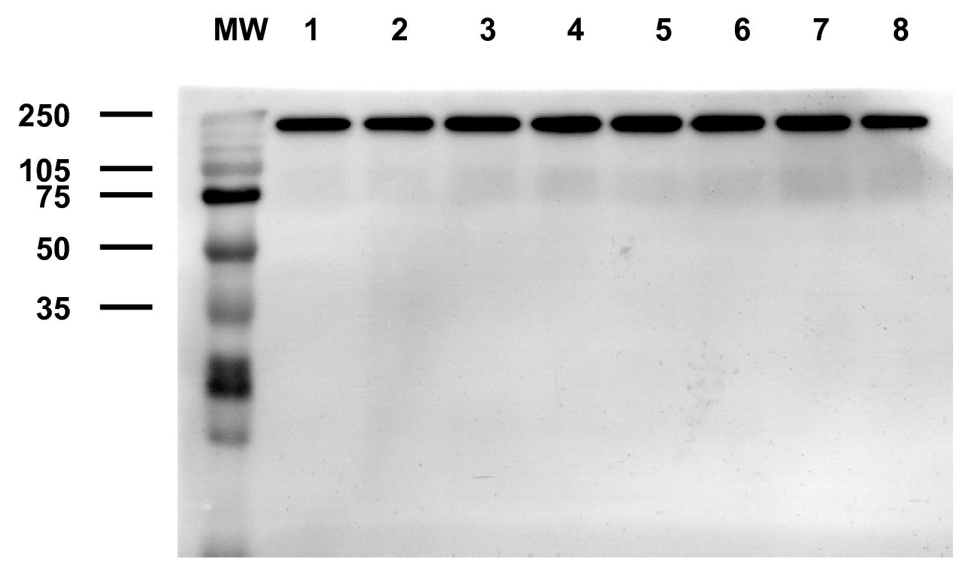

Figure 3 
Fig.4

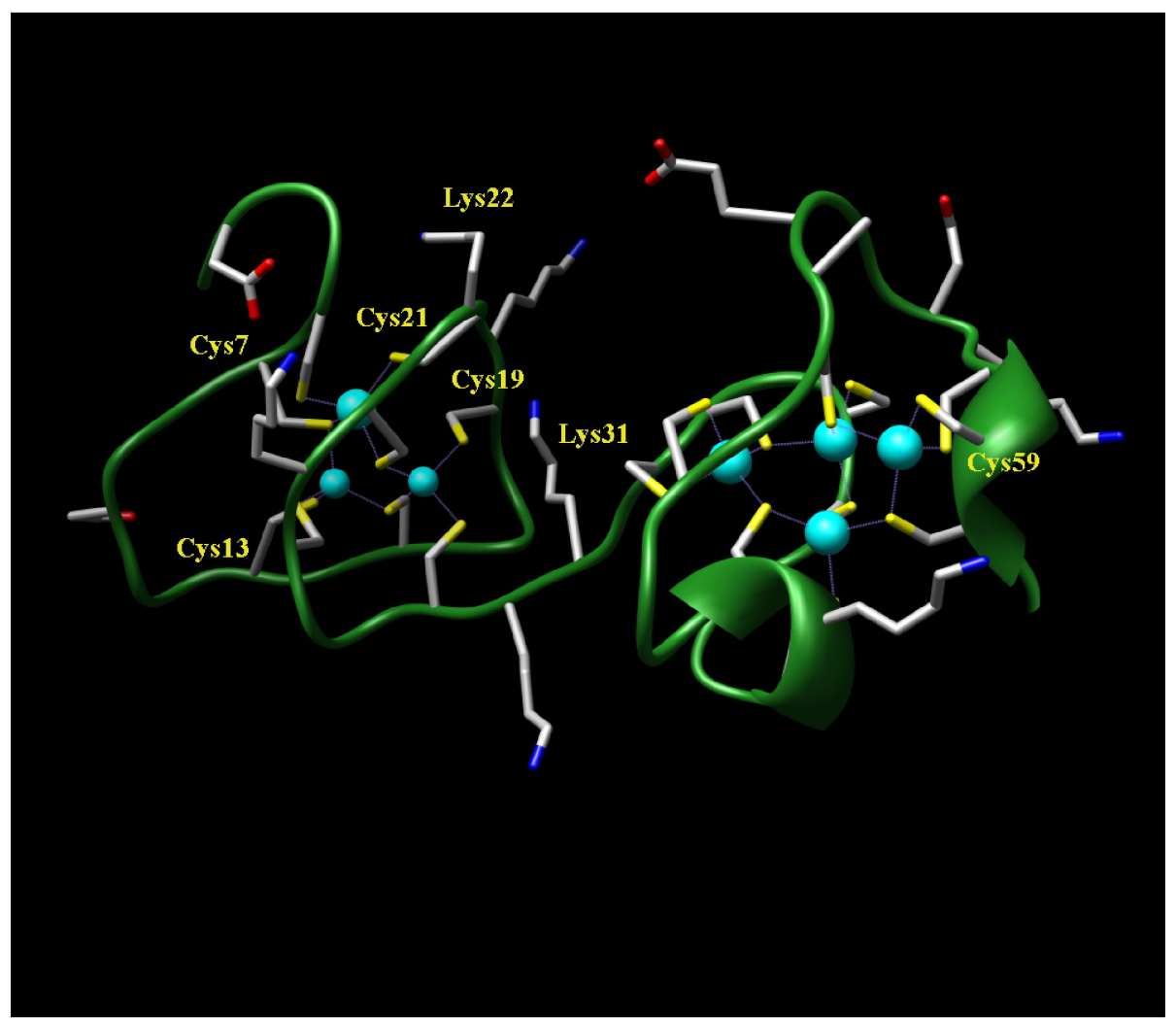

Figure 4 